\title{
Synthesis and Characterization of Mixed Ligand Complexes of Copper(II) with Adenine and Dicarboxylic Acids
}

\author{
Sumaia Abdullah, M. S. Rahman, Humaira Yeasmin, A. A. Shaikh and Pradip K. Bakshi* \\ Department of Chemistry, University of Dhaka, Dhaka 1000, Bangladesh
}

(Received : 25 January 2021; Accepted : 14 October 2021)

\begin{abstract}
Three mixed ligand complexes of copper(II) with adenine and dicarboxylic acids have been synthesized. The resulting complexes were characterized by their melting point, solubility, metal content analysis, FT-IR and UV-visible spectroscopy, magnetic measurement, thermal analysis, cyclic voltammetric measurement and X-ray powder diffraction study. The products are microcrystalline powder, slightly soluble in water and decompose at high temperature. Under experimental condition, the ligands adenine (Ade) behaves as a neutral ligand, whereas oxalic acid $\left(\mathrm{OxH}_{2}\right)$, succinic acid $\left(\mathrm{SucH}_{2}\right)$ and tartaric acid $\left(\right.$ TarH $\left.\mathrm{H}_{2}\right)$ are doubly deprotonated to form dianionic ligands that are coordinated to the $\mathrm{Cu}(\mathrm{II})$ ion. The $\mathrm{Cu}(\mathrm{II})$ content analysis of the complexes confine to their stoichiometry $\left[\mathrm{Cu}(\mathrm{Ade})(\mathrm{L})\left(\mathrm{H}_{2} \mathrm{O}\right)\right](\mathrm{L}=\mathrm{Ox}$, Suc, or Tar dianion). Electrochemical redox behavior of the complexes in their reaction medium was also examined. They exhibit quasi-reversible one-electron transfer processes.
\end{abstract}

Keywords: Nucleobase, Adenine, Dicarboxylic acid, Infrared spectrum, Magnetic susceptibility.

\section{Introduction}

Interactions of metal ions with nucleic acid become highly relevant when the transition metal compounds are applied as chemical probes in the nucleic acid biochemistry or in chemotherapy ${ }^{1}$. The two main types of nucleic acids are deoxyribonucleic acid (DNA) and ribonucleic acid (RNA), whose molecules consist of many nucleotides linked in a long chain. And again, a nucleotide is made up of three components: a nucleobase, a pentose sugar, and a phosphate group. Adenine ${ }^{2}$ is a derivative of purine, consisting of a fused pyrimidine-imidazole ring system with conjugated double bonds and is an essential nucleobase ${ }^{3-5}$ of both DNA and RNA. Since heterocyclic nitrogen of the nucleic acid bases carry lone electron pairs, they are good ligands for alkali/alkaline earth and transition metals cations ${ }^{6}$. Coordination of metal ions to purine bases with unsubstituted $\mathrm{N}(9)$ is preferentially first to $\mathrm{N}(9)$ (in bridge to $\mathrm{N}(3)$ ), then to $\mathrm{N}(7)$ and then to $\mathrm{N}(1)^{7}$. On the other hand, dicarboxylic acids contain two acidic functional groups. Partial or complete deprotonation of dicarboxylic acids makes them excellent candidates for coordination with metal ions in multi-coordinated ways. Addition of a di- or poly carboxylic acid, consisting of hydrogen bonding acceptor groups (-OOC-R-COO${ }^{-}$) in a reaction mixture of metal ion and nucleobase, reaction may take place in a more selective way.

Intramolecular interligand hydrogen bond (H-bond) among the ligands could affect the stability of the complexes. Marzilli and Kistenmacher have primarily demonstrated the importance of stereospecific interligand interactions as factors that affect the specific metal binding to nucleic acid bases, involving hydrogen bonding, electrostatic repulsions, and steric constraints ${ }^{8}$. K. Aoki et al. have demonstrated the validity of Marzilli and Kistenmacher's approach in which the base- or site-specific metal bonding in the $\left.\left[\mathrm{Rh}_{2} \text { (carboxylato or amidato }\right)_{4}(\text { nucleobase or its derivative })_{2}\right]$ system could be rationalized by interligand interactions ${ }^{9-12}$. In the [Ni(nta)(adeninium)(aqua)] $\mathrm{H}_{2} \mathrm{O}$ complex, the metal ion bonding to $\mathrm{N}(7)$ for unsubstituted adenine and in this $\mathrm{N}(7)$ bonded metal complex, an interligand $\mathrm{H}$-bond involving the $\mathrm{N}(6)$ amino substituent is commonly formed, with carboxylato oxygen(s) of nta ligand, strongly suggesting that the formation of interligand $\mathrm{H}$-bond(s) is a factor that determines the metal binding site, $\mathrm{N}(7)^{13}$. However, there is no information yet available in the literature on metal-mixed ligand complexes of adenine and dicarboxylic acids. An attempt has, therefore, been taken to study the interaction between $\mathrm{Cu}$ (II) ion and adenine in presence of a dicarboxylic acid. In this report, synthesis and structural characterization of $\mathrm{Cu}(\mathrm{II})$ complexes with adenine and dicarboxylic acid such as oxalic acid $\left(\mathrm{OxH}_{2}\right)$, succinic acid $\left(\mathrm{SucH}_{2}\right)$ or tartaric acid $\left(\mathrm{TarH}_{2}\right)$ are presented. The structural formulae of Ade, $\mathrm{OxH}_{2}$, $\mathrm{SucH}_{2}$, and $\mathrm{TarH}_{2}$ are given below:<smiles>Nc1ncnc2[nH]cnc12</smiles>

Adenine (Ade)<smiles>O=C(O)CCC(=O)O</smiles>

Succinic acid $\left(\mathrm{SucH}_{2}\right)$<smiles>O=C(O)C(=O)O</smiles>

Oxalic acid $\left(\mathrm{OxH}_{2}\right)$<smiles>O=C(O)C(O)C(O)C(=O)O</smiles>

Tartaric acid $\left(\mathrm{TarH}_{2}\right)$ 


\section{Experimental}

Chemicals

Adenine was procured from LOBA Chemie Pvt. Ltd., India; oxalic acid dihydrate from Uni-Chem, India; succinic acid from Thomas Baker (Chemicals) Ltd., India; tartaric acid from Sigma-Aldrich, China. Copper chloride dihydrate, hydrochloric acid, nitric acid, ammonia, and organic solvents etc., used in all synthetic and analytical work were analar grade. All chemicals were used as received.

\section{Methods and Equipments}

Melting points were recorded on a SMP11 electrothermal melting point apparatus, Shimadzu, Japan. The $\mathrm{Cu}(\mathrm{II})$ content of the complexes was determined complexometrically using $\mathrm{Na}_{2}$ EDTA. $2 \mathrm{H}_{2} \mathrm{O}$ as the titrating agent. Infrared (IR) spectra of the complexes were recorded on a Shimadzu (Japan) Infrared Spectrometer of model IR-470 in the range of $400-4000 \mathrm{~cm}^{-1}$ using $\mathrm{KBr}$ pellets. The UV-visible spectra of the complexes were recorded using UV-visible recording Spectrometer, Model UV-160A, Shimadzu (Japan), in the wavelength range of $200-600 \mathrm{~nm}$ using water as the reference solvent. Magnetic susceptibility of the complexes was determined by the SHERWOOD SCIENTIFIC Magnetic Susceptibility Balance (M.S.B.), Cambridge, England, Model: Magway MSB Mk1. The quasi-static thermogravimetric (QSTG) analysis was carried out in a CARBOLITE calibrated muffle furnace of the type CWF $11 / 5$. The thermo-gravimetric analysis (TGA) of the complexes was carried out with TGA-50 analyzer, Shimadzu (Japan) in the temperature range from $20^{\circ} \mathrm{C}$ to $700^{\circ} \mathrm{C}$ under nitrogen at a flow rate of $20 \mathrm{~mL} / \mathrm{min}$ and at a heating rate of $10^{\circ} \mathrm{C} / \mathrm{min}$. The differential scanning calorimetry (DSC) was performed on a Shimadzu Thermal Analyzer DT-40. Samples were placed in sealed aluminum pans and heated under nitrogen flow $(20 \mathrm{~mL} / \mathrm{min})$ at a heating rate of $10^{\circ} \mathrm{C} / \mathrm{min}$ from $50^{\circ} \mathrm{C}$ to $550^{\circ} \mathrm{C}$. An empty pan was used as a reference. Cyclic voltammetric measurement of the complexes was done using $\mathrm{CH}$ 620D Electroanalyzer and in Pyrex glass micro cell with a Teflon cap. Three electrode system, GCE as the working electrode, $\mathrm{Ag} / \mathrm{AgCl}$ (satd. $\mathrm{KCl}$ ) as the reference electrode and platinum wire as the counter electrode was employed for cyclic voltammetric investigation. Powder X-ray diffraction photograph of a complex was recorded in a PHILIPS PW1830 X-ray generator equipped with XDC-700 GuinierHägg camera, using nickel filtered $\mathrm{CuK}_{\alpha}$ radiation $(\lambda=$ $1.540981 \AA$ ).

\section{Synthesis of Complexes}

Mixed ligands complexes of copper(II) (adenine-aquadicarboxylato- $\mathrm{Cu}(\mathrm{II})$ ) were synthesized in aqueous/or methanolic solution and at ambient conditions. Aqueous/or methanolic solutions of copper(II) chloride dihydrate, adenine and dicarboxylic acid in 1:1:1 molar ratio were prepared by dissolving the requisite amount of them in minimum volume of hot distilled water/or methanol separately, mixed together and kept the resulting solution at ambient conditions for reaction. The products formed were isolated by filtration, washed with water, and dried in a desiccator over blue silica gel. A summarized synthetic procedure is given in Table1.

\section{Results and Discussion}

All complexes are air-stable and non-hygroscopic at ambient conditions. The empirical formulae of the complexes have been established on the basis of their $\mathrm{Cu}$ (II) contents. The products are microcrystalline in nature and slightly soluble in water. Some of their physical properties viz. yield, colour, melting point, $\mathrm{Cu}$ (II) contenthave been studied and are tabulated in Table 2.

Table 1. Nominal composition of reactants used for the preparation of complexes.

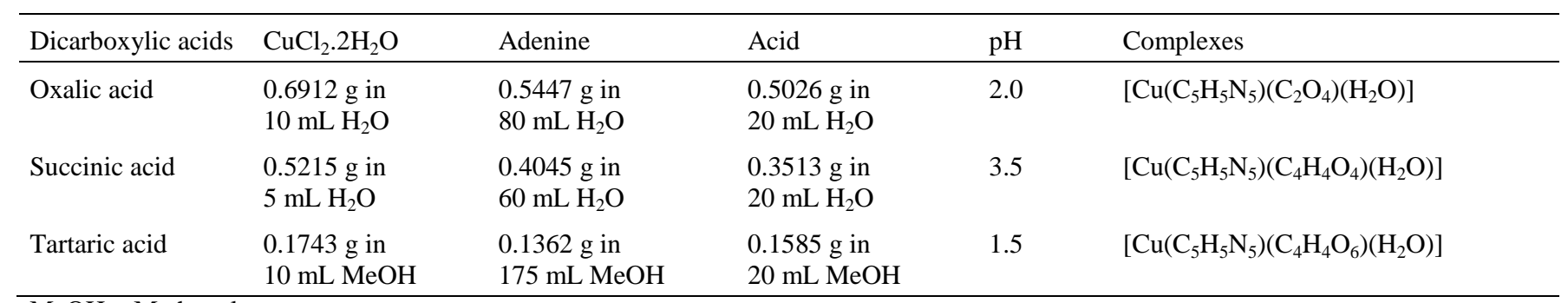

$\mathrm{MeOH}=$ Methanol

Table 2. Metal content and some physical properties of the complexes.

\begin{tabular}{lllll}
\hline Compounds & Yield* $/ \%$ & Colour & m.p. $/{ }^{\circ} \mathrm{C}$ & Metal content $/ \%$ \\
\hline$\left[\mathrm{Cu}(\right.$ Ade $\left.)(\mathrm{Ox})\left(\mathrm{H}_{2} \mathrm{O}\right)\right]$ & 38.1 & Sky blue & $156(\mathrm{~d})$ & $20.13(20.72)$ \\
{$\left[\mathrm{Cu}(\right.$ Ade $\left.)(\mathrm{Suc})\left(\mathrm{H}_{2} \mathrm{O}\right)\right]$} & 62.6 & Dark green & $195(\mathrm{~d})$ & $20.76(18.98)$ \\
{$\left[\mathrm{Cu}\right.$ (Ade) $\left.(\mathrm{Tar})\left(\mathrm{H}_{2} \mathrm{O}\right)\right]$} & 59.0 & Bluish green & $>250$ & $18.75(17.42)$ \\
\hline
\end{tabular}

Ade $=\mathrm{C}_{5} \mathrm{H}_{5} \mathrm{~N}_{5}, \mathrm{Ox}=\mathrm{C}_{2} \mathrm{O}_{4}{ }^{2-}$, Suc $=\mathrm{C}_{4} \mathrm{H}_{4} \mathrm{O}_{4}{ }^{2-}$ and $\mathrm{Tar}=\mathrm{C}_{4} \mathrm{H}_{4} \mathrm{O}_{6}{ }^{2-}$. $*$ The percentage of yield was calculated on the basis of $\mathrm{Cu}(\mathrm{II})$ content. =decomposition temperature. The calculated metal contents are in parentheses. 
Table 3. Tentative assignments ${ }^{14}$ of IR bands of adenine, dicarboxylic acids and their $\mathrm{Cu}(\mathrm{II})$ complexes.

\begin{tabular}{|c|c|c|c|c|c|c|c|c|}
\hline Compounds & $\begin{array}{l}\mathrm{v}(\mathrm{O}-\mathrm{H}) \\
/ \mathrm{cm}^{-1}\end{array}$ & $\begin{array}{l}\mathrm{v}(\mathrm{N}-\mathrm{H}) \\
/ \mathrm{cm}^{-1}\end{array}$ & $\begin{array}{l}v(>\mathrm{C}=\mathrm{O}) \\
/ \mathrm{cm}^{-1}\end{array}$ & $\begin{array}{l}v\left(>\mathrm{COO}^{-}\right) \\
/ \mathrm{cm}^{-1}\end{array}$ & $\begin{array}{l}\mathrm{v}(\mathrm{C}=\mathrm{N}) \\
/ \mathrm{cm}^{-1}\end{array}$ & $\begin{array}{l}\mathrm{v}(\mathrm{C}-\mathrm{N}) \\
/ \mathrm{cm}^{-1}\end{array}$ & $\begin{array}{l}\mathrm{v}(\mathrm{M}-\mathrm{N}) \\
/ \mathrm{cm}^{-1}\end{array}$ & $\begin{array}{l}\mathrm{v}(\mathrm{M}-\mathrm{O}) \\
/ \mathrm{cm}^{-1}\end{array}$ \\
\hline $\mathrm{OxH}_{2}$ & $3500-3000$ & & 1685 & & & & & \\
\hline $\mathrm{TarH}_{2}$ & $3650-3000$ & & 1736 & & & & & \\
\hline$\left[\mathrm{Cu}(\mathrm{Ade})(\mathrm{Ox})\left(\mathrm{H}_{2} \mathrm{O}\right)\right]$ & $3330-3175$ & & & 1661,1461 & 1550 & 1321 & 506 & 430 \\
\hline$\left[\mathrm{Cu}(\mathrm{Ade})(\mathrm{Suc})\left(\mathrm{H}_{2} \mathrm{O}\right)\right]$ & $3331-3190$ & & & 1646,1464 & 1604 & 1343 & 576 & 440 \\
\hline
\end{tabular}

\section{IR Spectral Analysis}

The prominent infrared spectral data of adenine, dicarboxylic acids and their $\mathrm{Cu}(\mathrm{II})$ complexes are presented in Table 3. The band assignments have been done on the basis of literature survey.

The broad peak(s) in the region $3650-2537 \mathrm{~cm}^{-1}$ indicates the presence of $\mathrm{O}-\mathrm{H}, \quad \mathrm{N}-\mathrm{H}$ and $\mathrm{C}-\mathrm{H}$ groups from inorganic/organic moieties. This broadening of the peak is as a consequence of peaks resulting from different merging groups as well as their interaction within. Formation of hydrogen bonding also results in broadened of $\mathrm{O}-\mathrm{H}$ and $\mathrm{N}-\mathrm{H}$ stretchings vibrations bands. In comparison with the spectra of ligands, their $\mathrm{Cu}(\mathrm{II})$ complexes show various vibrational frequencies at different positions and intensities indicating that the ligands are coordinated with $\mathrm{Cu}$ (II) ion. The characteristic i.r. band of carboxylic acid group observed at $1685-1736 \mathrm{~cm}^{-1}$ in the spectrum of free dicarboxylic acids, is absent in the spectra of their complexes. It supports that dicarboxylic acids are doubly deprotonated before coordination with metal ions in the complexes. The ligated $\mathrm{COO}^{-}$vibrates at about 1660 and $1462 \mathrm{~cm}^{-1}$ in the spectra of the complexes. The peak separations between $v_{\text {asym }}\left(-\mathrm{COO}^{-}\right)$ and $v_{\text {sym }}\left(-\mathrm{COO}^{-}\right)$are found $\sim 198 \mathrm{~cm}^{-1}$ which supported bisbidentate coordination modes of carboxylate groups. The $\mathrm{C}=\mathrm{N}$ peak appearing in the ligand at $1672 \mathrm{~cm}^{-1}$ is shifted to $1550-1604 \mathrm{~cm}^{-1}$ in the complexes. The shift of $v(\mathrm{C}=\mathrm{N})$ frequency values suggests that coordination between the $\mathrm{Cu}(\mathrm{II})$ and the adenine possibly occurs through imidazolyl nitrogen N(7) atom of the ligand.

The $v(\mathrm{Cu}-\mathrm{N})$ and $v(\mathrm{Cu}-\mathrm{O})$ vibrations of weak intensity appear in the region of $576-425 \mathrm{~cm}^{-1}$. The tetrahedral $\mathrm{Cu}$ (II) ion is build up possibly through dicarboxylate oxygens that occupy two of the four directional positions, an adenine ligand at the another directional position through the N(7) site, and the remaining tetrahedral directional position is occupied by a water molecule.

\section{$U V$-vis Spectral Analysis}

All three complexes are slightly soluble in water at room temperature. Their aqueous solutions were used for recording their electronic spectra. The spectral data of the complexes are tabulated in Table 4. The UV-visible spectral investigation shows that the complexes show an intense absorption band at $\sim 300 \mathrm{~nm}$ due to $\pi \rightarrow \pi^{*}$ and/or $\mathrm{n} \rightarrow \pi^{*}$ electronic transitions. Due to poor solubility in water the complexes do not show any band in the visible region.

Table 4. Electronic spectral data of the studied compounds.

\begin{tabular}{ll}
\hline Complexes & $\lambda / \mathrm{nm}$ \\
\hline$\left[\mathrm{Cu}(\right.$ Ade $\left.)(\mathrm{Ox})\left(\mathrm{H}_{2} \mathrm{O}\right)\right]$ & 302 \\
{$\left[\mathrm{Cu}(\right.$ Ade $\left.)(\mathrm{Suc})\left(\mathrm{H}_{2} \mathrm{O}\right)\right]$} & 308 \\
{$\left[\mathrm{Cu}(\right.$ Ade $\left.)(\mathrm{Tar})\left(\mathrm{H}_{2} \mathrm{O}\right)\right]$} & 322 \\
\hline
\end{tabular}

\section{Magnetic Susceptibility Measurement}

Magnetic measurements of the complexes were carried out, and the results are gathered in Table 5. The observed magnetic moment $\left(\mu_{\text {eff }}\right)$ of $\mathrm{Cu}(\mathrm{II})$ complexes are in the ranges of 1.60-1.64 $\mathrm{BM}$ correspond to the presence of one unpaired electron. $\mathrm{Cu}(\mathrm{II})$ is a $d^{9}$ cation with the $d$-electron configuration of $t_{2 g}{ }^{6} e_{g}^{3}$ irrespective of spin type as well as geometry of its complexes.

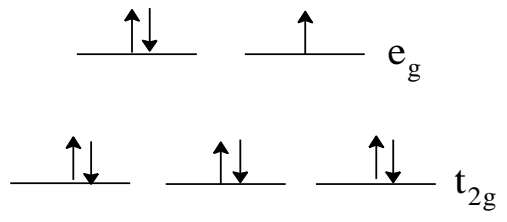

\section{Thermal Analysis}

The thermograms obtained from the quasi-static thermogravimetric analysis of the studied complexes are plotted in Fig. 1 for comparison. The thermograms show that all the studied $\mathrm{Cu}(\mathrm{II})$ complexes start losing weight at around $50^{\circ} \mathrm{C}$. Total weight loses up to $150^{\circ} \mathrm{C}$ are registered $6.38 \%$ for $\left[\mathrm{Cu}\right.$ (Ade) $\left.(\mathrm{Ox})\left(\mathrm{H}_{2} \mathrm{O}\right)\right], 5.78 \%$ for $\left[\mathrm{Cu}(\right.$ Ade $\left.)(\mathrm{Suc})\left(\mathrm{H}_{2} \mathrm{O}\right)\right]$ and $5.41 \%$ for $\left[\mathrm{Cu}\right.$ (Ade) $\left.(\mathrm{Tar})\left(\mathrm{H}_{2} \mathrm{O}\right)\right]$, corresponds to the removal of coordinately bonded water molecule from the complexes.

Table 5. Magnetic measurement data of the studied complexes at $32^{\circ} \mathrm{C}$.

\begin{tabular}{llllllll}
\hline Complexes & $\mathrm{C}_{\mathrm{Bal}}$ & $1, \mathrm{~cm}$ & $\mathrm{~m}, \mathrm{~g}$ & $\mathrm{R}$ & Ro & $\chi_{\mathrm{g}} \times 10^{-8}$, C.G.S. unit & $\mu_{\text {eff }}, \mathrm{BM}$ \\
\hline$\left[\mathrm{Cu}(\right.$ Ade $\left.)(\mathrm{Ox})\left(\mathrm{H}_{2} \mathrm{O}\right)\right]$ & 0.9963 & 2.3 & 0.0923 & 105 & -34 & 345.09 & 1.63 \\
{$\left[\mathrm{Cu}\left(\right.\right.$ Ade $\left.(\mathrm{Suc})\left(\mathrm{H}_{2} \mathrm{O}\right)\right]$} & 0.9927 & 2.2 & 0.1358 & 154 & -34 & 302.34 & 1.60 \\
{$\left[\mathrm{Cu}(\right.$ Ade $\left.)(\mathrm{Tar})\left(\mathrm{H}_{2} \mathrm{O}\right)\right]$} & 0.9954 & 2.0 & 0.1355 & 164 & -35 & 292.38 & 1.64 \\
\hline
\end{tabular}


Beyond that, the process of decomposition is relatively rapid and occurs in several steps suggesting that the ligands are lost in fragments. In spite of different colour of the products, the thermal decomposition of all three $\mathrm{Cu}(\mathrm{II})$ complexes ends in a black residue and attain a constant weight at about $400-450^{\circ} \mathrm{C}$. The residues are being identified as $\mathrm{CuO}$ by their chemical analysis. The overall weight loss observed is about $77 \%$, comparable with theoretical mass value. The way of the thermal decomposition of $\left[\mathrm{Cu}(\mathrm{Ade})(\mathrm{L})\left(\mathrm{H}_{2} \mathrm{O}\right)\right](\mathrm{L}=\mathrm{Ox}$, Suc, or Tar dianion) is as follows:

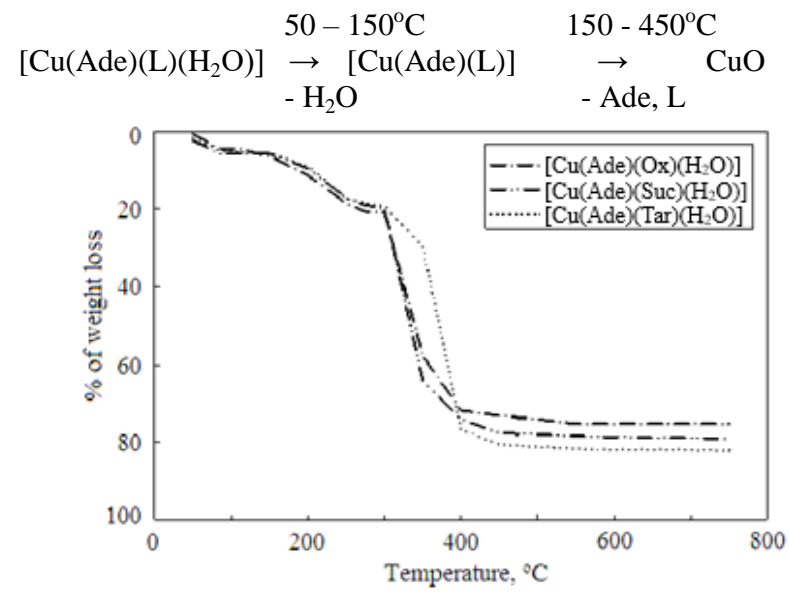

Fig. 1. QSTG graph of $\left[\mathrm{Cu}(\mathrm{Ade})(\mathrm{L})\left(\mathrm{H}_{2} \mathrm{O}\right)\right](\mathrm{L}=\mathrm{Ox}$, Suc, or Tar dianion).

The thermogravimetric analyses (TGA) of these complexes were also performed. A similar trend of thermal behavior of above complexes is observed. The differential scanning calorimetric (DSC) analysis shows that the decomposition processes are both endothermic and exothermic in nature.

\section{Cyclic Voltammetric Study}

Electrochemical behavior of $\mathrm{Cu}$ (II), and $\mathrm{Cu}$ (II) with adenine and dicarboxylic acid ligands at 1:1:1 molar ratio in $0.1 \mathrm{M} \mathrm{KCl}$ aqueous solution at GCE have been studied. The cyclic voltammogram $(\mathrm{CV})$ of $\mathrm{Cu}(\mathrm{II})$ in $0.1 \mathrm{M} \mathrm{KCl}$ solution with scan rate of $100 \mathrm{mVs}^{-1}$ within the potential window of $750 \mathrm{mV}$ to $-1000 \mathrm{mV}$ is shown in Fig. 2(solid line). In the forward scan, the voltammogram exhibits two cathodic peaks, $i_{p c 1}$ and $i_{p c 2}$ at about $180.45 \mathrm{mV}$ and $-395.87 \mathrm{mV}$ respectively, as well as in the reverse scan two anodic peaks, $i_{p a 1}$ and $i_{p a 2}$ at about $235.39 \mathrm{mV}$ and $-70.50 \mathrm{mV}$, are observed separately. Two cathodic peaks correspond to the reduction of $\mathrm{Cu}(\mathrm{II})$ to $\mathrm{Cu}(\mathrm{I})$ and $\mathrm{Cu}(\mathrm{I})$ to $\mathrm{Cu}(0)$ species while the two anodic peaks are due to the oxidation of $\mathrm{Cu}(0)$ to $\mathrm{Cu}(\mathrm{I})$ and $\mathrm{Cu}(\mathrm{I})$ to $\mathrm{Cu}(\mathrm{II})$ species. This behavior apparently reveals that the electrode system follows two step one-electron transfer electrode processes. These findings are in good agreement with the previous studies ${ }^{15}$. The variation of peak current with the square root of scan rate over the whole scan range demonstrates that the redox processes are diffusion controlled. Anodic peak and cathodic peak current ratio and the peak potential separation suggest that the $\mathrm{Cu}(\mathrm{II}) / \mathrm{Cu}(\mathrm{I})$ couple (corresponds to first pair) is reversible and the $\mathrm{Cu}(\mathrm{I}) / \mathrm{Cu}(0)$ (corresponds to second pair) is quasi-reversible redox system.

In presence of Ade and $\mathrm{SucH}_{2}$ ligands at 1:1:1 molar ratio ( $\mathrm{Cu}$ (II):Ade: $\mathrm{SucH}_{2}$ ), the voltammogram of $\mathrm{Cu}$ (II) was recorded in the identical condition and the obtained voltammogram is shown in Fig. 2(short dash). It is interesting that $\mathrm{CV}$ for the mixture exhibits only one cathodic peak (around $-400 \mathrm{mV}$ ) and two anodic peaks (around $280 \mathrm{mV}$ and $-180 \mathrm{mV}$ ). Although the CVs for Ade (dash) and $\mathrm{SucH}_{2}$ (dash dot) showed no peaks in the identical experimental conditions. The peak currents and the peak potentials of $\mathrm{Cu}$ (II) are shifted in presence of ligands relative to those of its free state, indicating metalligand interactions take place in the reaction medium. The peak potential separation increases with increasing scan rate (Fig. 3) because of quasi-reversible redox processes. The anodic peak associated with the oxidation process is intense indicates the oxidation of copper is greatly facilitated in the presence of Ade and $\mathrm{SucH}_{2}$ molecule.

$\mathrm{CVs}$ of $\mathrm{Cu}(\mathrm{II})$ ion, and $\mathrm{Cu}(\mathrm{II})$ in presence of Ade and $\mathrm{OxH}_{2}$ (Fig. 4), or $\mathrm{Cu}$ (II) ion, and $\mathrm{Cu}$ (II) along with Ade and $\mathrm{TarH}_{2}$ (Fig. 5) at identical experimental condition are also recorded and similar behavior is observed.

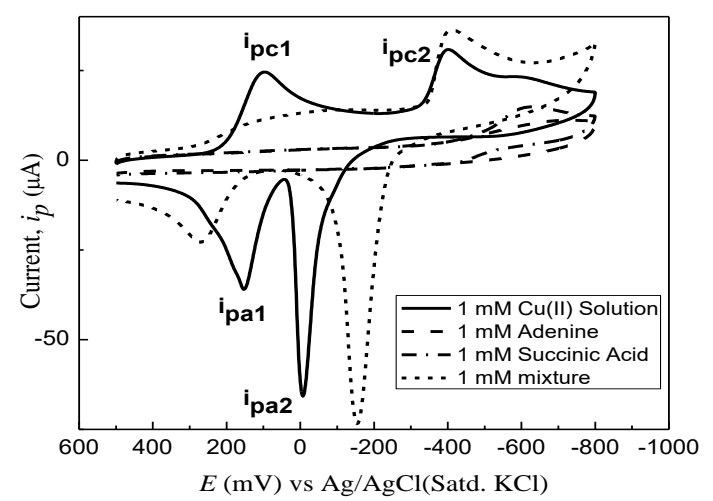

Fig. 2. Cyclic voltammograms of $\mathrm{Cu}(\mathrm{II})$ (solid), adenine(dash), succinic acid(dash dot), and $\mathrm{Cu}(\mathrm{II})$-ligands mixture(short dash) solution in $\mathrm{KCl}$ solution at the scan rate $100 \mathrm{mVs}^{-1}$.

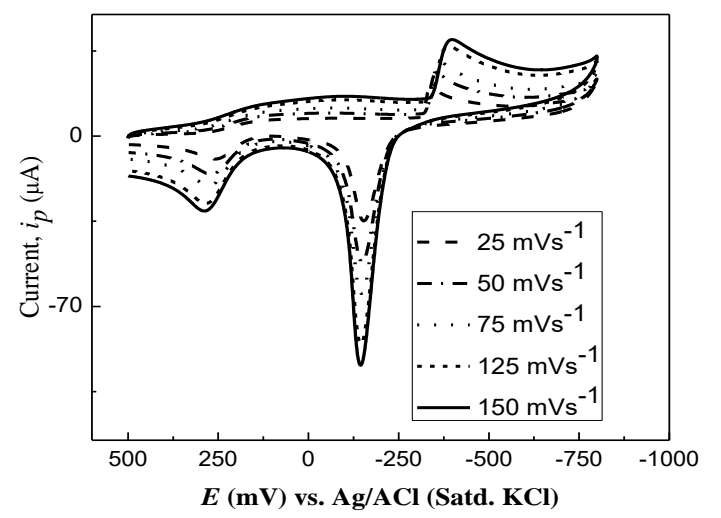

Fig. 3. Cyclic voltammograms of $\mathrm{Cu}(\mathrm{II})$ in presence of adenine and succinic acid at different scan rates 25(dash), 50(dash dot), 75(dot), 125(short dash) and 150 (solid) $\mathrm{mVs}^{-1}$. 


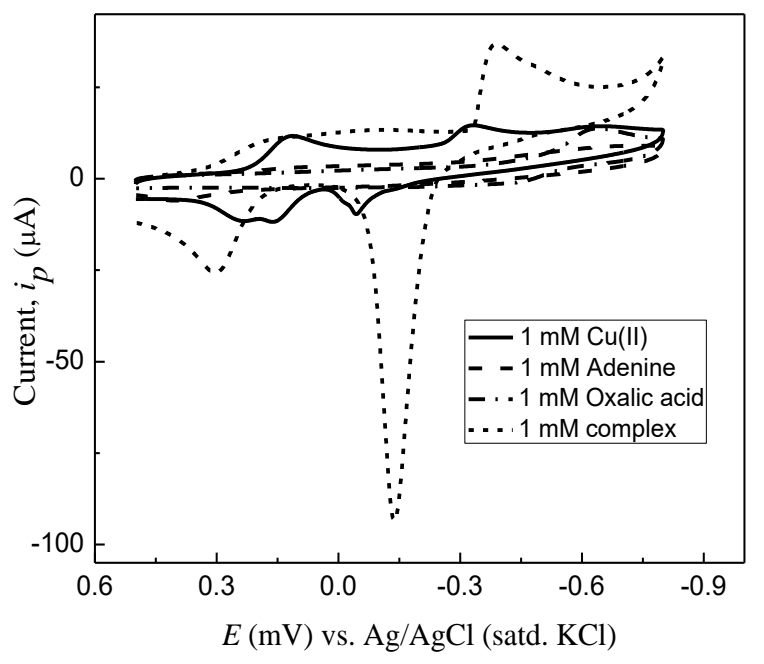

Fig. 4. Cyclic voltammograms of $\mathrm{Cu}$ (II)(solid), adenine(dash), oxalic acid(dash dot), and $\mathrm{Cu}$ (II)-ligands mixture(short dash) solution in $\mathrm{KCl}$ solution at the scan rate $100 \mathrm{mVs}^{1}$.

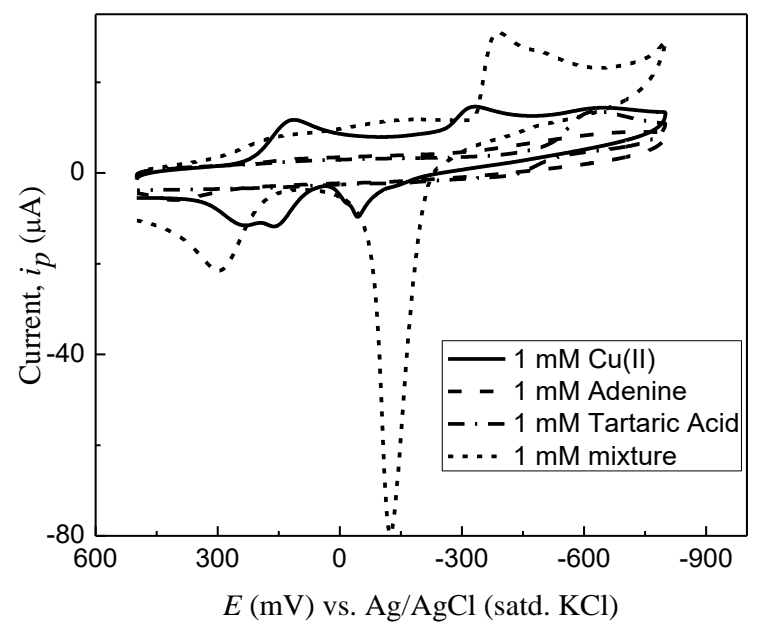

Fig. 5. Cyclic voltammograms of $\mathrm{Cu}$ (II)(solid), adenine(dash), tartaric acid(dash dot), and $\mathrm{Cu}$ (II)-ligands mixture(short dash) solution in $\mathrm{KCl}$ solution at the scan rate $100 \mathrm{mVs}^{-1}$.

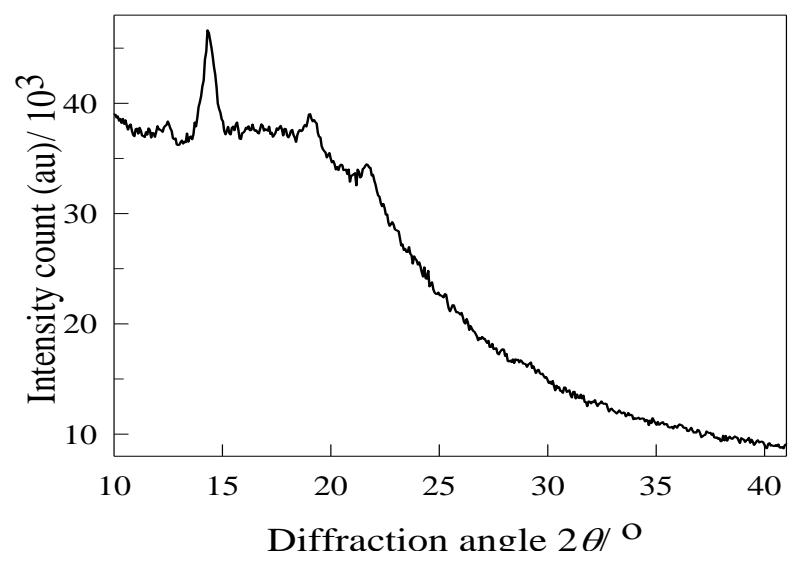

Fig. 6. X-ray powder diffraction of $\left[\mathrm{Cu}(\mathrm{Ade})(\mathrm{Suc})\left(\mathrm{H}_{2} \mathrm{O}\right)\right]$.

\section{X-ray Powder Diffraction Studies}

The X-ray powder diffraction of only [Cu(Ade) $\left.(\mathrm{Suc})\left(\mathrm{H}_{2} \mathrm{O}\right)\right]$ complex shows a few observable weak diffraction lines (Fig. 6). The $d$-values of them were calculated. These are presented in Table 6 . The cause of showing a few weak lines is that either the complex belongs to a high symmetry crystal system, or it is a poorly crystallin solid which do not diffract well.

Table 6. The $d$-values calculated from powder X-ray diffraction of $\left[\mathrm{Cu}(\mathrm{Ade})(\mathrm{Suc})\left(\mathrm{H}_{2} \mathrm{O}\right)\right]$.

\begin{tabular}{llll}
\hline Relative intensity & $l / \mathrm{mm}$ & $\theta /^{\circ}$ & Calcd. $d / \AA$ \\
\hline Strong & 24.43 & 7.16 & 6.18 \\
Medium & 32.51 & 9.52 & 4.66 \\
Weak & 36.95 & 10.82 & 4.10 \\
\hline
\end{tabular}

\section{Conclusion}

Reaction of copper(II) with adenine and a dicarboxylic acid like oxalic acid, succinic acid or tartaric acid in aqueous/methanol medium yielded complexes with the proposed formula of $\left[\mathrm{Cu}(\right.$ Ade $\left.)(\mathrm{L})\left(\mathrm{H}_{2} \mathrm{O}\right)\right](\mathrm{L}=\mathrm{Ox}$, Suc or Tar dianions). Investigation of their physico-chemical properties indicates that adenine act as a neutral ligand and dicarboxylic acids act as bidentate anionic ligand after doubly deprotonation. Adenine is coordinated with $\mathrm{Cu}(\mathrm{II})$ through $\mathrm{N}(7)$ of its imidazolyl ring nitrogen, dicarboxylate anions through carboxylate oxygens and probably there is also an interligand hydrogen-bonding between exocyclic $\mathrm{H}_{2} \mathrm{~N}(6)$ group with dicarboxylate anion. In major cases, adenine coordinates to metal ion through $\mathrm{N}(9)$ or through $\mathrm{N}(9)$ and $\mathrm{N}(3)$, and in minor cases, through $\mathrm{N}(7)$ and through $\mathrm{N}(3)$. In case of $\left[\mathrm{Cu}(\right.$ Ade $\left.)(\mathrm{L})\left(\mathrm{H}_{2} \mathrm{O}\right)\right]$ (where $\mathrm{L}=\mathrm{Ox}$, Suc or Tar dianions) complex the $\mathrm{Cu}$ (II) ion shows a coordinating behavior selective for $\mathrm{N}(7)$ over $\mathrm{N}(9)$ with adenine. This siteselectivity may be caused by interligand interactions such as hydrogen-bonding and electrostatic repulsion associated with the steric environment about the $\mathrm{Cu}$ (II) ion. Suitable single crystal preparation and their structural data collection is still our plan to reemphasis the hypothesis on metal ioninterligand interactions. Based on our experimental results and earlier reports, the most probable structures of the studied compounds are given below:

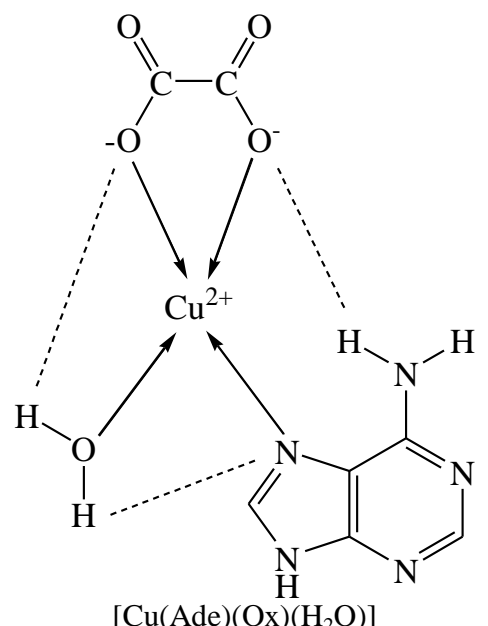



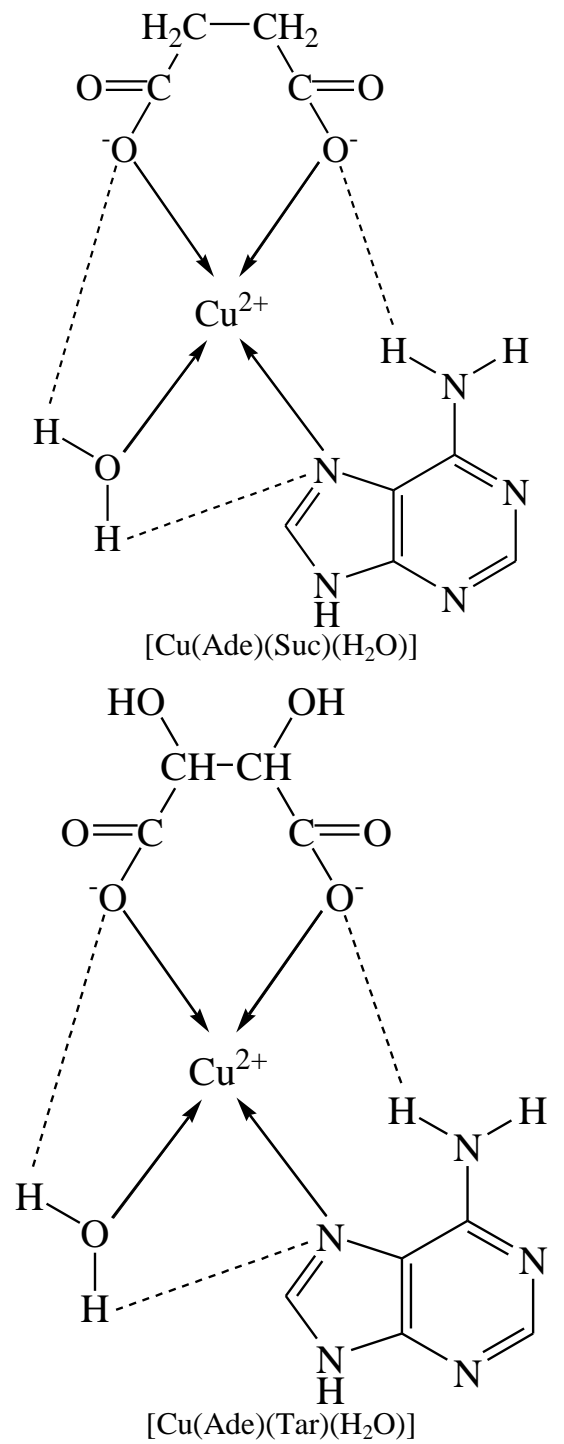

\section{References}

1. Sissoëff, I., J. Grisvard and E. Guillé, 1976. Studies on metal ions- DNA interactions: specific behaviour of reiterative DNA sequences. Prog. Biophys. Molec. Biol., 31(2), 165199.

2. Shaprio, R., 1995. The prebioticrole of adenine: a critical analysis. Origins of Life and Evolution of Biospheres.25(13), 83-98.

3. Elson, D., 1965. Metabolism of nucleic acids (macromolecular DNA and RNA). Ann. Rev. Biochem., 34, 449-486.

4. Yakovchuk, P., E. Protozanova and M. D. Frank-Kamenetskii, 2006. Base-stacking and base-pairing contributions into thermal stability of the DNA double helix. Nucleic Acids Res., 34(2), 564-574.
5. Ilavarasi, R., M. N. S. Rao and M. R. Udupa, 1997. Synthesis and characterization of copper(II) complexes of adenine and amino acids. Proceedings of the Indian Academy of Sciences - Chemical Sciences, 109(2), 79-87.

6. Brown, E. A. and C. E. Bugg, 1980. Calcium binding to nucleotides: structure of a hydrated calcium salt of inosine-5'monophosphate. Acta Crystallogr., B 36, 2597-2604.

7. Izatt, R. M., J. J. Christensen and J. H. Rytting, 1971. Sites and thermodynamic quantities associated with proton and metal ion interaction with ribonucleic acid, deoxyribonucleic acid, and their constituent bases, nucleosides, and nucleotides. Chem. Rev.,71(5), 439-481.

8. Marzilli, L.G. and T.J. Kistenmacher, 1977. Stereoselectivity in the binding of transition-metal chelate complexes to nucleic acid constituents: bonding and nonbonding effects. Acc. Chem. Res.10, 146-152.

9. Aoki, K. and H. Yamazaki, 1980. Interactions of tetrakis(- $\mu-$ carboxylato)dirhodium(II), an antitumour agent, with nucleic acid bases. X-ray crystal structures of $\left[\mathrm{Rh}_{2} \text { (acetato }\right)_{4}$ (theophylline $\left.)_{2}\right]$ and $\left[\mathrm{Rh}_{2}(\text { acetato })_{4}(\text { caffeine })_{2}\right]$. J. Chem. Soc., Chem. Commun., 186-188.

10. Aoki, K. and H. Yamazaki, 1984. Stereospecific interactions between tetrakis( $\mu$-carboxylato)dirhodium antitumor agents and nucleic acid bases. Crystal structure of the rhodium complex $\left.\left[\mathrm{Rh}_{2} \text { (acetato }\right)_{4}(\mathrm{AAMP}) \cdot 3.5 \mathrm{H}_{2} \mathrm{O}\right](\mathrm{AAMP}=4$-amino5-(aminomethyl)-2-methylpyrimidine). J. Am. Chem. Soc., 106(12), 3691-3692.

11. Aoki, K., M. Hoshino, T. Okada, H. Yamazaki, and H. Sekizawa, 1986. Interligand interactions affecting specific metal bonding to nucleic acid bases: X-ray crystal structure of tetrakis- $\mu$-acetamidatobis(theophylline)rhodium(II)-rhodium (III) nitrate monohydrate. J. Chem. Soc., Chem. Commun., 314-316.

12. Aoki, K., M. Inaba, S. Teratani, H. Yamazaki, and Y. Miyashita, 1994. Interligand interactions affecting sitespecific metal bonding. X-ray crystal structures of $\left.\left[\mathrm{Rh}_{2} \text { (acetato }\right)_{4}(\mathrm{~L})_{2}\right]$, where $\mathrm{L}=$ 2,4-diamino-6-methyl-striazine, 2,6-dimethyl-4-aminopyrimidine, and 2,6dimethylpyridine. Inorg. Chem., 33(13), 3018-3020.

13. Salam, M. A. and K. Aoki, 2000. Interligand interactions affecting specific metal bonding to nucleic acid bases: the tripodal nitrilotriacetato (nta) ligand-system. Crystal structures of [(nta)(adeninium)(aqua)nickel(II)] hydrate, [(nta)(diaqua) nickel (II)] ( cytosinium)hydrate, and [(nta) (diaqua)nickel (II)]. (cytosinium). (cytosine) hydrate. Inorganica Chim. Acta, 311(1-2), 15-24.

14. Pavia, D. L., G. P. Lampman and G. S. Kriz, 2000. Introduction to Spectroscopy. $3^{\text {rd }}$ Edition, Washington.

15. Haque F., M. S. Rahman, E. Ahmed, P. K. Bakshi and A. A. Shaikh, 2013. A cyclic voltammetric study of the redox reaction of $\mathrm{Cu}(\mathrm{II})$ in presence of ascorbic acid in different $\mathrm{pH}$ media, Dhaka Univ. J. Sci., 61(2), 161-166. 